\title{
Modelling Monetary Policy: Inflation Targeting in Practice
}

\author{
Christopher Martin \\ Costas Milas \\ Department of Economics and Finance, \\ Brunel University \\ Uxbridge \\ Middlesex UB8 3PH
}

September 2001

\begin{abstract}
This paper estimates a simple structural model of monetary policy in the UK for 1963-2000, focusing on the policy of inflation targeting introduced in 1992. Our main findings are: i) the adoption of inflation targets led to significant changes in monetary policy giving greater weight to inflation; (ii) monetary policy post-1992 is asymmetric as policy makers respond more to upward deviation of inflation away from the target; (iii) in the post-1992 period policymakers may be attempting to keep inflation within the range of $1.4 \%-2.6 \%$ rather than pursuing a point target of $2.5 \%$; (iv) monetary policy is more responsive to inflation when it is further from the target.
\end{abstract}

JEL: C51; C52; E52; E58

Keywords: monetary policy, inflation targeting

email: christopher.martin@brunel.ac.uk, costas.milas@brunel.ac.uk 


\section{Modelling Monetary Policy: Inflation Targeting in Practice}

\section{1) Introduction}

In the decade since they were first introduced, inflation targets have proved to be a valuable aspect of monetary policy and are now used in over 20 countries. Developed countries with inflation targets have largely succeeded in maintaining low inflation while also experiencing less output volatility, an improved sacrifice ratio and more predictable monetary policy. The verdict on inflation targets has thus far been positive (see Bernanke et al, 1999, Mishkin and Schmidt-Herbel, 2001 and Corbo et al, 2001). To quote Mervyn King: "inflation targets form a clear and transparent framework for monetary policy ...I think they are here to stay" (King 1997).

This paper considers a number of issues related to inflation targeting. First, has the adoption of inflation targets affected monetary policy? We might expect an increased weight to be placed on inflation and a correspondingly lower weight to be placed on output. Has this happened? Second, is the policy symmetric, so deviations of inflation above and below the target are seen as equally bad? Third, do policymakers attempt to hit the inflation target precisely or do they aim to keep inflation within a target range? Fourth, is monetary policy more responsive to inflation when it is further from the target, or is the policy response always linear?

We address these issues using a simple non-linear structural framework to analyse UK monetary policy between 1963 and 2000, focussing on the policy of inflation targeting introduced in 1992. Our main conclusions are: (i) The adoption of inflation targets led to significant changes in monetary policy. Prior to 1992, the influence of output was stronger than that of inflation; after 1992 we find that the influence of inflation was much increased while output has no effect. (ii) Monetary policy post-1992 is asymmetric as policy makers respond more to upward deviation of inflation away from the target than to downward deviations. (iii) In the post-1992 period policymakers may be attempting to keep inflation within the range of $1.4 \%-2.6 \%$ rather than pursuing a point target of $2.5 \%$. (iv) Monetary policy is more responsive to inflation when it is further from the target.

The remainder of the paper is organised as follows. Section 2 presents our model and explains how it can be used to address the issues raised above. Section 3 presents our results and discusses the implications for these issues. Section 4 summarises and concludes. 


\section{2a) Monetary Policy in the UK since 1992}

Since late 1992, the main aim of monetary policy in the UK has been to achieve low and stable inflation (for details, see Bernanke et al, 1999). The policy goal announced in October 1992 was to keep inflation within target bands of $1 \%$ and $4 \%$, with the aim of achieving inflation below $2.5 \%$ within a time horizon of five years. In 1995, an explicit medium-term target of $2.5 \%$ was introduced. In May 1997, the Bank of England was given operational independence and the target range was abolished, to be replaced by the sanction that the governor of the Central Bank would have to write an explanatory letter if inflation rose above $3.5 \%$ or fell below $1.5 \%$.

In the light of this discussion, we model monetary policy in the period since October 1992 as follows:

$$
\dot{i}_{\mathrm{t}}=\mathrm{i}^{*}+\theta_{\mathrm{t}} \mathrm{M}_{1 \mathrm{t}}+\left(1-\theta_{\mathrm{t}}\right) \mathrm{M}_{2 \mathrm{t}}
$$

where

$$
\mathrm{M}_{2 \mathrm{t}}=\beta_{1} \mathrm{i}_{\mathrm{t}-1}+\beta_{2}\left(\pi_{\mathrm{t}+1}^{\mathrm{e}}-\pi^{\mathrm{T}}\right)+\beta_{3}(\mathrm{y}-\mathrm{y} *)_{\mathrm{t}-1}
$$

and

$$
\theta_{\mathrm{t}}=\operatorname{pr}\left\{\pi^{\mathrm{T}}-\pi^{1} \leq \pi_{\mathrm{t}+1}^{\mathrm{e}} \leq \pi^{\mathrm{T}}+\pi^{2}\right\}
$$

where $\mathrm{i}$ is the nominal interest rate, $\mathrm{i}^{*}$ is a constant, $\mathrm{M}_{1}$ is the "inner regime", $\mathrm{M}_{2}$ is the "outer regime", $\theta$ is the relative weight on the inner regime, $\pi$ is inflation, $\pi^{\mathrm{e}}$ is expected inflation, $\pi^{\mathrm{T}}$ is the inflation target, $\mathrm{y}$ is output, $\mathrm{y}^{*}$ is trend output and $\mathrm{t}$ indexes time. We will estimate the $\alpha$ and $\beta$ parameters, $i^{*}, \pi^{1}$ and $\pi^{2}$.

Equation (1) relates the interest rate to a weighted average of $\mathbf{M}_{1}$ and $\mathbf{M}_{2}$. Equations (2) and (3) describe $M_{1}$ and $M_{2}$ as Taylor-like policy rules (Taylor, 1993) that relate interest rates to inflation and output. Equation (4) equates the regime weight $\theta$ to the probability that expected inflation will lie between the bands $\left(\pi^{\mathrm{T}}-\pi^{1}\right)$ and $\left(\pi^{\mathrm{T}}+\pi^{2}\right)$. To illustrate this, if it is known with certainty that inflation will (resp. will not) be between the bands, then policy is determined by $\mathrm{M}_{1}$ 
(resp. $\mathrm{M}_{2}$ ). In general, the weight on $\mathrm{M}_{1}$ is greater the larger is the probability that expected inflation will lie between $\left(\pi^{T}-\pi^{1}\right)$ and $\left(\pi^{T}+\pi^{2}\right)$. As a result, we can think of $M_{1}$ as the policy rule for interest rates when expected inflation is viewed as acceptable and $\mathbf{M}_{2}$ as the policy rule when it is not. If one regime is always dominant, our simplifies to a familiar Taylor rule model of monetary policy.

Both the Taylor-like rules in equations (2) and (3) and the equation for the regime weights in (4) have expected inflation relative to the target as an argument. Our use of this forward-looking measure reflects the practice of the Monetary Policy Committee of the Bank of England as revealed in the minutes of their monthly meeting. It also reflects theoretical work that stresses the importance of inflation forecasts for monetary policy (Svensson, 1997, 1997a, Batini and Haldane, 1999, and Rudebusch and Svensson, 1999). Our specification is also consistent with the results of Nelson (2000), who finds a forward-looking Taylor rule outperforms a backward-looking rule in the period 1992-1997.

2b) Monetary Policy before 1992

We use a similar approach in developing a model of monetary policy for the period before inflation targets were introduced in October 1992. We specify our model as

$$
\dot{i}_{t}=i^{*}+\lambda_{t} M_{3 t}+\left(1-\lambda_{t}\right) M_{4 t}
$$

where

$$
\mathrm{M}_{4 \mathrm{t}}=\delta_{1} \mathrm{i}_{\mathrm{t}-1}+\delta_{2} \pi_{\mathrm{t}+1}^{\mathrm{e}}+\delta_{3}(\mathrm{y}-\mathrm{y} *)_{\mathrm{t}-1}
$$

and

$$
\lambda_{\mathrm{t}}=\operatorname{pr}\left\{\pi^{3} \leq \pi_{\mathrm{t}+1}^{\mathrm{e}} \leq \pi^{4}\right\}
$$

The only substantive difference here is that we do not include an inflation target. Clearly, we could investigate different sub-regimes for the pre-1992 period, however the main focus of this paper is on inflation targeting, so this is left for future work. 


\section{2c) Discussion}

This model allows us to address the issues raised in the introduction. We can investigate how the conduct of monetary policy has changed since the introduction of inflation targets by considering differences in the estimated parameters between regimes. If policy has altered since 1992 such that more importance is attached to inflation and correspondingly less importance attached to output, then $\gamma_{3}>\alpha_{3}, \delta_{3}>\beta_{3}, \gamma_{2}<\alpha_{2}$ and $\delta_{2}<\beta_{2}$. An increased priority given to inflation might also be reflected in a narrowing of the regime boundaries; if so, $\pi^{3}<\left(\pi^{T}-\pi^{1}\right)$ and $\pi^{4}>$ $\left(\pi^{\mathrm{T}}+\pi^{2}\right)$.

If monetary policy were symmetric post-1992, we would expect $\pi^{1}=\pi^{2}$, implying that deviations of inflation from the target in either direction are seen as equally bad. If $\pi^{2}<\pi^{1}$, then policymakers would be more sensitive to upward deviations of inflation from target, making the policy asymmetric. If $\pi^{1}=\pi^{\mathrm{T}}$, there is no effective lower band for inflation and the policy is onesided. We can also compare the regime boundaries with the bands within which inflation is permitted to fluctuate. If the requirement that the Governor writes an open explanatory letter if inflation rises above $3.5 \%$ or below $1.5 \%$ affects the behaviour of policymakers, we would expect both $\pi^{1}$ and $\pi^{2}$ to be less than unity.

We can examine whether policymakers are pursuing a point target or a target range (see Mishkin and Posen, 1997, Bernanke et al, 1999). If policymakers are attempting to keep inflation within the range of $\left(\pi^{T}-\pi^{1}\right)$ to $\left(\pi^{T}+\pi^{2}\right)$, then $\beta_{2}>0$ and $\alpha_{2}=0$ which implies monetary policy only responds to inflation when inflation lies outside the regime bands. If policymakers are aiming at a precise value of inflation, then $\beta_{2}>0$ and $\alpha_{2}>0$ which implies monetary policy always strives to move inflation towards the target. Finally, we can examine whether monetary policy responds more to expected inflation when inflation is further away from the target by testing whether $\beta_{2}>\alpha_{2}$ after 1992 and $\delta_{2}>\gamma_{2}$ before 1992 .

We model the regime weights using the quadratic logistic functions

$$
\theta_{\mathrm{t}}=1-\left[1+\exp \left\{-\sigma\left(\pi_{\mathrm{t}+1}^{\mathrm{e}}-\pi^{\mathrm{T}}-\pi^{1}\right)\left(\pi_{\mathrm{t}+1}^{\mathrm{e}}-\pi^{\mathrm{T}}-\pi^{2}\right)\right\}\right]^{-1}
$$

and

$$
\lambda_{\mathrm{t}}=1-\left[1+\exp \left\{-\sigma_{2}\left(\pi_{\mathrm{t}+1}^{\mathrm{e}}-\pi^{3}\right)\left(\pi_{\mathrm{t}+1}^{\mathrm{e}}-\pi^{4}\right)\right\}\right]^{-1}
$$


These functions have the properties that (considering (9a)) (i) $\theta$ becomes constant as $\sigma \rightarrow 0$ and (ii) as $\sigma \rightarrow \infty, \theta=0$ if $\pi_{t+1}^{\mathrm{e}}-\pi^{\mathrm{T}}<\pi^{1}$ or $\pi_{\mathrm{t}+1^{-}}^{\mathrm{e}}-\pi^{\mathrm{T}}>\pi^{2}$ and $\theta=1$ if $\pi^{1}<\pi_{\mathrm{t}+1^{-}}^{\mathrm{e}}-\pi^{\mathrm{T}}<\pi^{2}$ (see Jansen and Teräsvirta, 1996). We could use alternative functional forms, for example, we could model $\theta$ using the logistic function:

$$
\theta_{\mathrm{t}}=1-\left[1+\exp \left\{-\sigma\left(\pi_{\mathrm{t}+1^{-}}^{\mathrm{e}}-\pi^{\mathrm{T}}-\pi^{1}\right)\right\}\right]^{-1}
$$

This assumes asymmetric adjustment to positive and negative deviations of $\pi_{t+1}^{\mathrm{e}}-\pi^{\mathrm{T}}$ relative to a single bound $\pi^{1}$. We could also use the exponential function:

$$
\theta_{\mathrm{t}}=\exp \left\{-\sigma\left(\pi_{\left.\left.\mathrm{t}+1^{\mathrm{e}}-\pi^{\mathrm{T}}-\pi^{1}\right)^{2}\right\}}\right.\right.
$$

which assumes asymmetric adjustment to small and large absolute values of $\pi_{t+1}^{\mathrm{e}}-\pi^{\mathrm{T}}$. We prefer (9a) to these alternatives as it allows us to estimate separate upper and lower bands ${ }^{1}$.

Our model has similarities with STAR (Smooth Transition Auto-Regressive) models (Granger and Terasvirta, 1993, van Dijk et al, 2001) in that the endogenous variable is determined by a weighted average of two regimes with endogenous regime weights. Our approach differs from STAR models in using a forward-looking variable to determine the regime weights and in not considering a system of equations. Bec et al (2000) use a STAR representation to model monetary policy in the US, France and Germany. They allow monetary policy to vary between periods of "boom" and "slump", modelling the regime weights using a logistic function with a single threshold similar to $(9 \mathrm{c})$ to model the regime weights. They assume that the regime weights depend on the lagged output gap.

\section{$\underline{3 \text { Results }}$}

\section{3a) Data and estimation}

We use quarterly data for 1963Q1-2000Q1. We use the 3 month treasury bill rate as the nominal interest rate (this has a close relationship with the various interest rate instruments used over this period; see Nelson, 2000), inflation is the annual change in the retail price index and output is measured using the GDP deflator. We model the output gap as the difference between

\footnotetext{
${ }^{1}$ In addition, (9d) has the drawback that it becomes linear for extreme values of the $\sigma$ parameter (van Dijk et al, 2001).
} 
output and a Hodrick-Prescott trend. In estimation we replace expected future inflation with actual future inflation and use lagged variables as instruments.

Preliminary unit root analysis (the results are not reported but are available on request) showed that inflation and the output gap are stationary variables (see also Nelson, 2000, Driver, Greenslade and Pierse, 2000 and Hendry, 2001). The order of integration of the interest rate is more ambiguous, but we treat this variable as stationary (see also Fuhrer (1997) and Fuhrer and Moore (1995) for discussion of similar issues).

We estimate equations (1)-(4) using quarterly data for 1992Q4-2000Q1 and estimate equations (5)-(8) using data for 1963Q1-1992Q3. We follow Granger and Teräsvirta (1993) and Teräsvirta (1994) in making $\sigma$ dimension-free by dividing it by the variance of $\pi_{t+1}^{\mathrm{e}}$. In addition, van Dijk et al (2001) argue that the likelihood is very insensitive to $\sigma$, suggesting that precise estimation of this parameter is unlikely in our relatively short sample. For this reason, we do not attempt to use estimates of $\sigma$ to test our model against the alternative of a linear model.

Because of the short sample size in the post 1992Q3 period and our use of a heavily parameterised non-linear model, estimates of the full model were poorly determined. When the least significant variables were removed, we obtained a well-determined simplified model, estimates of which are presented in Table 1. Column (i) presents non-linear least squares estimates and column (ii) presents corresponding non-linear IV estimates. As can be seen from Table 1, use of non-linear IV estimation makes little difference to our results. The diagnostic tests show no serious mispecification ${ }^{3}$. The implied values of the regime weights $\lambda$ and $\theta$ are presented in Figures 1a) and 1b).

\section{3b) Results}

We find that that $\gamma_{3}>\alpha_{3}, \delta_{2}<\beta_{2}, \pi^{3}<\left(\pi^{\mathrm{T}}-\pi^{1}\right)$ and $\pi^{4}>\left(\pi^{\mathrm{T}}+\pi^{2}\right)$, implying that monetary policy changed after 1992, giving more priority to inflation and less to output. For 1963Q11992Q3, we estimate that $\pi^{3}=0.68 \%$ and $\pi^{4}=21.2 \%$. These bands are very wide and imply as figure 1a) shows, that the inner regime was dominant for most of this period; the outer regime received

${ }^{2}$ Based on this scaling, we use $\sigma=1$ as a starting value. Values of $\pi_{t+1}^{\mathrm{e}}$ close to its minimum are used as starting values for the $\pi^{1}$ and $\pi^{3}$ parameters, whereas values of $\pi^{\mathrm{e}}{ }_{\mathrm{t}+1}$ close to its maximum are used as starting values for the $\pi^{2}$ and $\pi^{4}$ parameters.

${ }^{3}$ There is a slight normality issue, due mainly to a large residual in 1985Q1. This period saw a large increase in the interest rate following rapid depreciation of the exchange rate and the reintroduction of activated the Minimum Lending Rate requirement at a higher level. 
significant weight only in 1975. Estimates of the $\gamma$ parameters reveal that output is the main concern of policymakers in the inner regime, with little or no weight attached to inflation. By contrast, inflation is the only significant variable in the outer regime. For 1992Q4- 2000Q1, we estimate the bands are $\left(\pi^{\mathrm{T}}-\pi^{1}\right)=1.4 \%$ and $\left(\pi^{\mathrm{T}}+\pi^{2}\right)=2.6 \%$. This marked narrowing of the regime bands is reflected, as figure $1 \mathrm{~b}$ ) shows, in a greater importance of the outer regime which has been dominant in several periods since 1992, most notably, 1994Q4-1995Q4 and 1996Q4-1998Q3 and in late 1999. The inner regime $\mathbf{M}_{1}$ depends only on the lagged interest rate. The outer regime $\mathbf{M}_{2}$ depends on lagged interest rates and expected future inflation, where the weight on expected future inflation is large. The output gap is no longer relevant to monetary policy.

For the post-1992 period our estimate of the upper band is only $0.1 \%$ above the inflation target, implying that the outer regime becomes important when expected inflation rises only slightly above the target. By contrast the lower band is $1.1 \%$ below the target. As a result, our estimates suggest that the inflation targeting regime has been asymmetric, with greater priority attached to increases in inflation above the target than to decreases below the target. Our finding of asymmetry may be due to the asymmetric nature of the inflation target between 1992-1995, when the medium term aim was inflation of $2.5 \%$ or less. That argument suggests the estimated lower bound would be higher if the model were estimated from 1995 (we might expect the lower bound to be greater than $1.5 \%$ after May 1997). We do not yet have sufficient data to test this.

Our finding that $\beta_{2}>0$ and $\alpha_{2}=0$ suggests that policymakers attempt to keep inflation within the estimated regime bands of $1.4 \%-2.6 \%$ and do not attempt to achieve the target rate of 2.5\%. This finding may again reflect the influence of the 1992-1995 period, when there was a target range rather than a precise target. If so, we would expect to find $\alpha_{2}>0$ when we have enough data to estimate the model from 1995 onwards.

Finally, our estimates suggest that monetary policy is more sensitive to inflation when it was further from the target in other regimes, as $\beta_{2}>\alpha_{2}$ and $\delta_{2}>\gamma_{2}$. The nonlinear impact of inflation on monetary policy is illustrated in Figure 2, where we depict the impact of expected inflation relative to the target on interest rates. This is calculated as

$$
\rho_{\mathrm{t}}=\theta_{\mathrm{t}} \alpha_{2}+\left(1-\theta_{\mathrm{t}}\right) \beta_{2}
$$

From figure 2, we observe that when expected inflation exceeds the upper bound of $2.6 \%$ in 1994Q3-1995Q4 and 1996Q4-1998Q2, $\rho$ increases from zero to 0.67 as the parameter on expected inflation switches from $\alpha_{2}$ to $\beta_{2}$. It is noteworthy that interest rates rose in 1994Q3, fell in 1995Q4, 
rose again in 1996Q4 and again fell in 1998Q2-Q3. Expected inflation was below the lower bound of 1.4\% in 1993Q1 and in 1999Q1-Q2. Interest rates fell in 1993Q1, although it is hard to distinguish this from the sustained fall in rates from 1989Q4-1993Q4. Interest rates also fell in 199Q1 but it is again hard to distinguish this from the sustained reduction that started in 1989Q4. Our model therefore seems to be reasonably accurate in predicting changes in interest rates.

\section{3c) Sensitivity Analysis}

Table 2 presents estimates of other specifications of our model (we only report the regime bands for convenience; other estimates are available form the authors on request). First, we estimate a model that uses lagged inflation $\left(\pi_{t-1}\right)$ rather than expected inflation $\left(\pi_{t+1}^{\mathrm{e}}\right)$ in equations (1)-(9). As can be seen from column (i) of Table 2, the estimated bands are highly implausible. This supports our forward-looking specification (see also Nelson, 2000). Second, we examined whether the output gap is forward-looking by using $\left(y-y^{*}\right)^{e}{ }_{t+1}$ (replaced in estimation with the actual output gap and using the lagged variable as an instrument) rather than the lagged output gap in equations (1)-(9) (see column (ii) of Table 2). This makes little difference to the estimated bounds but introduces autocorrelation and ARCH effects in the estimated model. Third, we used an alternative measure of the inflation rate, the annual change in the GDP price deflator. This makes little difference to our results. As can be seen from column (iii) of Table 2, the estimated bands are very similar to those reported in Table 1, as are estimates of the other parameters. Fourth, in column (iv) of Table 2, we use an alternative measure of the interest rate, namely the 3-month interbank rate. This has little affect for the post-1992 period where the bands are estimated as $1.43 \%$ and $2.63 \%$, but the lower band for the pre-1992 period is very poorly determined. We also used other measures of the output gap, including deviations of real GDP from linear, quadratic and cubic trends. Results (not reported here) are again similar to those in Table 1. We also experimented with including various measures of the exchange rate as additional arguments in (2), (3), (6) and (7) as some models of UK monetary policy using Taylor rules find a role for these (c.f. Clarida et al, 1998 and Nelson, 2000). We did not find any significant effects.

\section{3d) Comparison with Taylor rules}

Finally, we compare our results to those from a simple Taylor rule. Estimates of Taylor rules for 1963Q1-1992Q3 and 1992Q4-2000Q1 are presented in Table 3. For the pre-1992 period, estimates of our model are similar to those of a Taylor rule. This is not surprising as the inner regime was dominant for most of this period. For the post-1992 period, where the influence of 
regimes is more balanced, there is a difference in the estimates. Our model has a lower standard error and the fitted value is a better predictor of the actual interest rate than with the Taylor rule $(\mathrm{RMSE}=0.234$ as compared to $\mathrm{RMSE}=0.365$ for the Taylor rule). Stability tests (not reported) show that estimates of our model do not suffer from instability whereas the stability of the estimated Taylor rules is more questionable (see Bec et al, 2000, for a discussion of the implications of this for the Lucas Critique). In summary, our model appears to provide a better explanation of monetary policy over this period.

It is also possible to examine some of the issues considered above using Taylor rules. In Table 3, we find that the effect of inflation was small and insignificant in the pre-1992 period but large and significant post-1992. The output gap is significant before 1992 but insignificant thereafter. This confirms our finding that there were substantial changes in monetary policy after 1992.

As an alternative approach to testing whether inflation targeting is symmetric, we could use a $\left(\pi_{t+1}^{\mathrm{e}}-\pi^{\mathrm{T}}\right)^{+}$and $\left(\pi_{\mathrm{t}+1^{-}}^{\mathrm{e}}-\pi^{\mathrm{T}}\right)^{-}$as separate regressors in estimates of a Taylor Rule, where $\left(\pi_{\mathrm{t}+1^{-}}^{\mathrm{e}} \pi^{\mathrm{T}}\right)^{+}$is $\left(\pi_{t+1}^{\mathrm{e}}-\pi^{\mathrm{T}}\right)$ if deviations are positive and 0 else and $\left(\pi_{\mathrm{t}+1}^{\mathrm{e}}-\pi^{\mathrm{T}}\right)^{-}$is $\left(\pi_{\mathrm{t}+1^{-}}^{\mathrm{e}} \pi^{\mathrm{T}}\right)$ if deviations are negative and 0 else. Symmetry would imply that the estimated coefficients on these variables are the same. Estimates of this model are presented in Table 4 (we report OLS estimates for convenience; IV estimates are less well determined). Estimates of the augmented Taylor rule model that includes

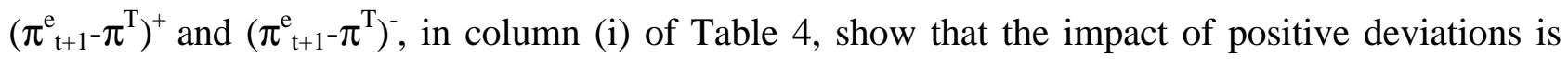
larger. This is again consistent with the estimates in Table 1, suggesting an asymmetric policy regime where movements of inflation above the target lead to a more vigorous policy response.

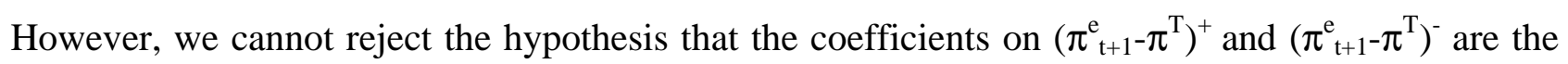
same.

We can also test for a nonlinear response of interest rates to inflation by including quadratic effects. Estimates of an augmented Taylor rule model that includes $\left(\pi_{t+1}^{e}-\pi^{T}\right)$ and $\left(\pi_{t+1}^{e}-\pi^{T}\right)^{2}$ for the post-1992 period and $\pi_{\mathrm{t}+1}^{\mathrm{e}}$ and $\pi_{\mathrm{t}+1}^{\mathrm{e}}$ for the pre-1992 period are reported in columns (ii) and (iii) of Table 4. Estimates on the quadratic terms are insignificant in both periods. In summary, although we can address the issues raised above using Taylor rules, we prefer our methodology as it is based on a unified framework with a clear structural interpretation and also provides more decisive results. The Taylor rules described in this section can be regarded as first-order approximations to our model; see Terasvirta, 1998). 


\section{4) Conclusions}

In this paper, we have estimated a simple structural model of monetary policy in the UK for 1963-2000, focusing on the policy of inflation targeting introduced in 1992. We document the changes in monetary policy following the adoption of an inflation targeting regime in 1992. We argue that inflation targeting in practice has been asymmetric, suggest that monetary policy throughout this period has responded more to inflation when it is further from the target and speculate that in the post1992 period policymakers may have been attempting to keep inflation within the range of $1.4 \%$ $2.6 \%$ rather than pursuing a point target of $2.5 \%$. We have also shown how our model provides clearer answers to these questions than more familiar Taylor rules of monetary policy.

Our work can be extended in several ways. First, it would be interesting to decompose monetary policy before 1992 into different sub-regimes, perhaps allowing for shifts in policy following the move from fixed to flexible exchange rates in the early 1970's and following the adoption and subsequent abandoning of money supply targeting. Second, it would be interesting to explore changes in monetary policy within the inflation targeting regime, after the adoption of a point target in 1995 and after the move to operational independence of the Central Bank in 1997. We intend to explore these issues in future work. 
Table 1(a)

Parameter Estimates for 1963Q1-1992Q3

$i_{\mathrm{t}}=i^{*}+\lambda_{\mathrm{t}} \mathrm{M}_{3 \mathrm{t}}+\left(1-\lambda_{\mathrm{t}}\right) \mathrm{M}_{4 \mathrm{t}}$, where $\mathrm{M}_{3 \mathrm{t}}=\gamma_{1} \mathrm{i}_{\mathrm{t}-1}+\gamma_{2} \pi_{\mathrm{t}+1}^{\mathrm{e}}+\gamma_{3}\left(\mathrm{y}-\mathrm{y}^{*}\right)_{\mathrm{t}-1}$, $\mathrm{M}_{4 \mathrm{t}}=\delta_{1} \mathrm{i}_{\mathrm{t}-1}+\delta_{2} \pi_{\mathrm{t}+1}^{\mathrm{e}}+\delta_{3}\left(\mathrm{y}-\mathrm{y}^{*}\right)_{\mathrm{t}-1}$ and $\lambda_{\mathrm{t}}=1-\left[1+\exp \left\{-\sigma\left(\pi_{\mathrm{t}+1}^{\mathrm{e}}-\pi^{3}\right)\left(\pi_{\mathrm{t}+1}^{\mathrm{e}}-\pi^{4}\right)\right\}\right]^{-1}$

\begin{tabular}{|l|l|l|}
\hline & \multicolumn{1}{|c|}{ (i) } & \multicolumn{1}{c|}{ (ii) } \\
\hline & $\begin{array}{l}\text { Non-linear Least } \\
\text { Squares estimates }\end{array}$ & $\begin{array}{l}\text { non-linear IV } \\
\text { estimates }\end{array}$ \\
\hline & $1.21(0.45)$ & $1.21(0.40)$ \\
\hline$i^{*}$ & $0.85(0.05)$ & $0.89(0.05)$ \\
\hline$\gamma_{1}$ & $0.04(0.03)$ & $-0.01(0.05)$ \\
\hline$\gamma_{2}$ & $0.18(0.08)$ & $0.22(0.09)$ \\
\hline$\gamma_{3}$ & - & - \\
\hline$\delta_{1}$ & $0.39(0.05)$ & $0.46(0.07)$ \\
\hline$\delta_{2}$ & - & - \\
\hline$\delta_{3}$ & $0.68(0.84)$ & $0.68(0.84)$ \\
\hline$\pi_{3}$ & $21.20(1.19)$ & $21.20(1.19)$ \\
\hline$\pi_{4}$ & $2.84(5.15)$ & $2.84(5.15)$ \\
\hline$\sigma$ & & 1.26 \\
\hline & 1.26 & $1.14[0.34]$ \\
\hline s.e. & $1.34[0.25]$ & $1.07[0.37]$ \\
\hline F ar & $1.38[0.25]$ & $16.37[0.00]$ \\
\hline F arch & $14.27[0.00]$ & $2.96[0.01]$ \\
\hline$\chi^{2}$ nd & $1.53[0.12]$ & \\
\hline F het & & \\
\hline & & \\
\hline
\end{tabular}

Notes: Number in parentheses are the standard errors of the estimates. $\sigma$ is made dimension-free by dividing it by the variance of $\pi_{t+1}^{\mathrm{e}}$. F ar is the Lagrange Multiplier $\mathrm{F}$ test for residual serial correlation of up to fifth order. $\mathrm{F}$ arch is the fifth order Autoregressive Conditional Heteroscedasticity $\mathrm{F}$ test. $\chi^{2}$ nd is a Chi-square test for normality. $\mathrm{F}$ het is an $\mathrm{F}$ test for heteroscedasticity. Numbers in square brackets are the probability values of the test statistics. 
Table 1(b)

Parameter Estimates for 1992Q4-2000Q1

$\mathrm{i}_{\mathrm{t}}=\mathrm{i}^{*}+\theta_{\mathrm{t}} \mathrm{M}_{1 \mathrm{t}}+\left(1-\theta_{\mathrm{t}}\right) \mathrm{M}_{2 \mathrm{t}}$, where $\mathrm{M}_{1 \mathrm{t}}=\alpha_{1} \mathrm{i}_{\mathrm{t}-1}+\alpha_{2}\left(\pi_{\mathrm{t}+1}^{\mathrm{e}}-\pi^{\mathrm{T}}\right)+\alpha_{3}\left(\mathrm{y}-\mathrm{y}^{*}\right)_{\mathrm{t}-1}$,

$\mathrm{M}_{2 \mathrm{t}}=\beta_{1} \mathrm{i}_{\mathrm{t}-1}+\beta_{2}\left(\pi_{\mathrm{t}+1}^{\mathrm{e}}-\pi^{\mathrm{T}}\right)+\beta_{3}\left(\mathrm{y}-\mathrm{y}^{*}\right)_{\mathrm{t}-1}$ and $\theta_{\mathrm{t}}=1-\left[1+\exp \left\{-\sigma\left(\pi_{\mathrm{t}+1}^{\mathrm{e}}-\pi^{\mathrm{T}}-\pi^{1}\right)\left(\pi_{\mathrm{t}+1}^{\mathrm{e}}-\pi^{\mathrm{T}}-\pi^{2}\right)\right\}\right]^{-1}$

\begin{tabular}{|l|l|l|}
\hline & \multicolumn{1}{|c|}{ (i) } & \multicolumn{1}{c|}{ (ii) } \\
\hline & $\begin{array}{l}\text { non-linear Least } \\
\text { Squares estimates }\end{array}$ & $\begin{array}{l}\text { non-linear IV } \\
\text { estimates }\end{array}$ \\
\hline i* $^{*}$ & $3.17(0.34)$ & $3.20(0.36)$ \\
\hline$\alpha_{1}$ & $0.40(0.06)$ & $0.40(0.07)$ \\
\hline$\alpha_{2}$ & - & - \\
\hline$\alpha_{3}$ & - & - \\
\hline$\beta_{1}$ & $0.47(0.06)$ & $0.45(0.06)$ \\
\hline$\beta_{2}$ & $0.58(0.08)$ & $0.67(0.14)$ \\
\hline$\beta_{3}$ & - & - \\
\hline$\pi_{1}$ & $1.10(0.04)$ & $1.10(0.04)$ \\
\hline$\pi_{2}$ & $0.11(0.01)$ & $0.11(0.01)$ \\
\hline$\sigma$ & $90.22(616.52)$ & $90.22(616.52)$ \\
\hline & & \\
\hline s.e. & 0.24 & 0.24 \\
\hline F ar & $0.19[0.96]$ & $1.47[0.91]$ \\
\hline F arch & $0.25[0.91]$ & $0.51[0.73]$ \\
\hline$\chi^{2}$ nd & $4.09[0.13]$ & $1.81[0.40]$ \\
\hline F het & $0.26[0.98]$ & $0.64[0.64]$ \\
\hline
\end{tabular}

Notes: See the notes of Table 1a. 
Table 2

Estimates of alternative specifications

a) Sample period: 1963Q1-1992Q3

\begin{tabular}{|l|l|l|l|l|}
\hline & \multicolumn{1}{|c|}{ (i) } & \multicolumn{1}{|c|}{ (ii) } & \multicolumn{1}{c|}{ (iii) } \\
\hline & $\begin{array}{l}\text { Model with lagged } \\
\text { inflation }\end{array}$ & $\begin{array}{l}\text { Model with forward- } \\
\text { looking output gap }\end{array}$ & $\begin{array}{l}\text { Inflation measured } \\
\text { by GDP deflator }\end{array}$ & $\begin{array}{l}\text { Interest rate } \\
\text { measured } \\
\text { by interbank rate }\end{array}$ \\
\hline$\pi_{3}$ & $-219.63(0.68)$ & $0.53(1.13)$ & $1.44(0.40)$ & $-29.95(648.24)$ \\
\hline$\pi_{4}$ & $19.59(21.20)$ & $21.49(2.52)$ & $24.50(0.89)$ & $21.80(0.62)$ \\
\hline
\end{tabular}

b) Sample period: 1992Q4-2000Q1

\begin{tabular}{|l|l|l|l|l|}
\hline & \multicolumn{1}{|c|}{ (i) } & \multicolumn{1}{|c|}{ (ii) } & \multicolumn{1}{c|}{ (iii) } \\
\hline & $\begin{array}{l}\text { Model with lagged } \\
\text { inflation }\end{array}$ & $\begin{array}{l}\text { Model with forward- } \\
\text { looking output gap }\end{array}$ & $\begin{array}{l}\text { Inflation measured } \\
\text { by GDP deflator }\end{array}$ & $\begin{array}{l}\text { Interest rate } \\
\text { measured } \\
\text { by interbank rate }\end{array}$ \\
\hline$\pi_{1}$ & $1.41(16.27)$ & $1.10(0.04)$ & $0.86(0.40)$ & $1.07(0.10)$ \\
\hline$\pi_{2}$ & $-0.05(451.08)$ & $0.11(0.01)$ & $0.10(0.14)$ & $0.13(0.23)$ \\
\hline
\end{tabular}

Notes: See the notes of Table 1a. 
Table 3

Estimates of simple Taylor rules

\begin{tabular}{|l|l|l|l|l|}
\hline & \multicolumn{2}{|c|}{ 1963Q1-1992Q3 } & \multicolumn{1}{c|}{ 1992Q4-2000Q1 } \\
\hline & $\begin{array}{l}\text { Least Squares } \\
\text { estimates }\end{array}$ & IV estimates & \multicolumn{1}{c|}{ (iii) } & \multicolumn{1}{c|}{$\begin{array}{l}\text { Least Squares } \\
\text { estimates }\end{array}$} \\
\hline & & & & IV estimates \\
\hline $\mathrm{i}^{*}$ & $1.11(0.38)$ & $1.13(0.39)$ & $2.99(0.39)$ & $1.32(0.66)$ \\
\hline $\mathrm{i}_{\mathrm{t}-1}$ & $0.86(0.04)$ & $0.87(0.04)$ & $0.49(0.06)$ & $0.43(0.10)$ \\
\hline$\pi_{\mathrm{t}+1}^{\mathrm{e}}$ & $0.04(0.03)$ & $0.01(0.03)$ & & \\
\hline$\left(\pi^{\mathrm{e}}{ }_{\mathrm{t}+1}-\pi^{\mathrm{T}}\right)$ & & & $0.51(0.10)$ & $0.79(0.34)$ \\
\hline$\left(\mathrm{y}-\mathrm{y}^{*}\right)_{\mathrm{t}-1}$ & $0.18(0.08)$ & $0.19(0.08)$ & $0.07(0.08)$ & $-0.08(0.19)$ \\
\hline & & & & 0.33 \\
\hline s.e. & 1.26 & 1.26 & 0.29 & $0.41[0.83]$ \\
\hline F ar & $1.79[0.12]$ & $1.92[0.10]$ & $0.77[0.58]$ & $0.34[0.85]$ \\
\hline F arch & $1.21[0.30]$ & $1.20[0.31]$ & $0.61[0.65]$ & $0.50[0.78]$ \\
\hline$\chi^{2}$ nd & $12.06[0.00]$ & $10.43[0.00]$ & $0.57[0.75]$ & $1.30[0.30]$ \\
\hline F het & $2.84[0.01]$ & $2.79[0.01]$ & $0.25[0.95]$ & \\
\hline
\end{tabular}

Notes: See the notes of Table 1a. 
Table 4

Estimates of augmented Taylor rules

\begin{tabular}{|c|c|c|c|}
\hline & 1992Q4-2000Q1 & 1992Q4-2000Q1 & 1963Q1-1992Q3 \\
\hline & (i) & (ii) & (iii) \\
\hline & Least Squares estimates & Least Squares estimates & Least Squares estimates \\
\hline$i^{*}$ & $2.99(0.37)$ & $2.97(0.38)$ & $0.76(0.47)$ \\
\hline$\left(\pi_{t+1}^{e}-\pi^{T}\right)^{+}$ & $0.74(0.17)$ & & \\
\hline$\left(\pi_{t+1}^{\mathrm{e}}-\pi^{\mathrm{T}}\right)^{-}$ & $0.32(0.15)$ & & \\
\hline$\left(\pi^{\mathrm{e}}{ }_{t+1}-\pi^{\mathrm{T}}\right)$ & & $0.52(0.10)$ & \\
\hline$\left(\pi_{t+1}^{e}-\pi^{T}\right)^{2}$ & & $0.14(0.09)$ & \\
\hline$\pi_{t+1}^{e}$ & & & $0.16(0.10)$ \\
\hline$\pi_{t+1}^{e}$ & & & $-0.00(0.01)$ \\
\hline$i_{t-1}$ & $0.47(0.06)$ & $0.48(0.06)$ & $0.84(0.04)$ \\
\hline$\left(y-y^{*}\right)_{t-1}$ & $0.07(0.07)$ & $0.07(0.08)$ & $0.16(0.08)$ \\
\hline s.e. & 0.28 & 0.28 & 1.26 \\
\hline$\chi^{2}$ eq & $2.85[0.09]$ & & \\
\hline $\mathrm{F}$ ar & $0.64[0.67]$ & $0.60[0.70]$ & $1.39[0.23]$ \\
\hline $\mathrm{F}$ arch & $0.28[0.88]$ & $0.35[0.84]$ & $1.69[0.16]$ \\
\hline$\chi^{2} \mathrm{nd}$ & $0.75[0.68]$ & $0.72[0.69]$ & $11.28[0.00]$ \\
\hline F het & $0.19[0.98]$ & $0.19[0.98]$ & $4.24[0.00]$ \\
\hline
\end{tabular}

Notes:

1) See the notes of Table 1a.

2) $\chi^{2}$ eq is a chi-square test of the hypothesis that the coefficients on $\left(\pi_{t+1}^{e} \pi^{T}\right)^{+}$and $\left(\pi^{e}{ }_{t+1}-\pi^{T}\right)^{-}$are equal. 
Figure 1a) Estimates of $\lambda$

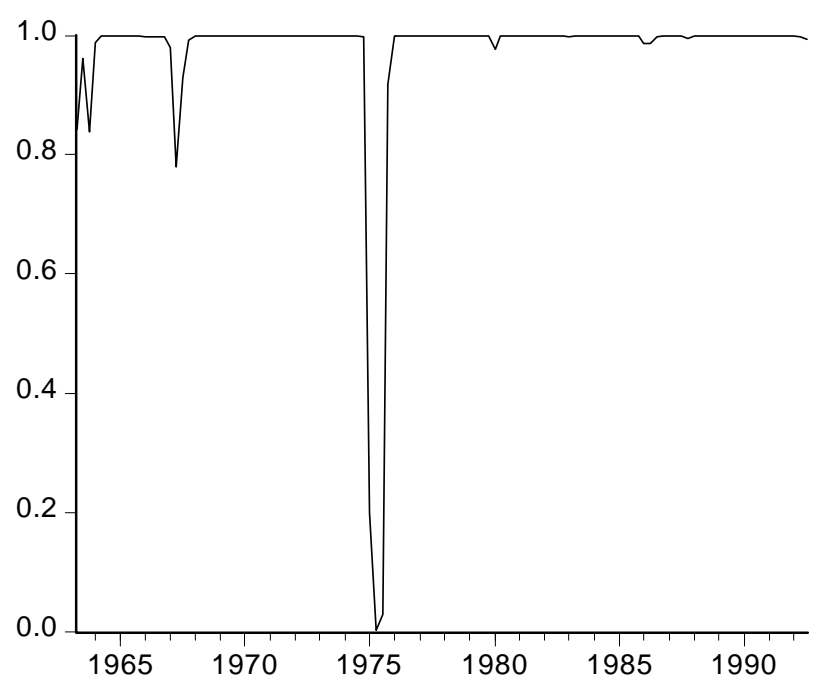

Note: $\lambda_{\mathrm{t}}=1-\left[1+\exp \left\{-\sigma\left(\pi_{\mathrm{t}+1}^{\mathrm{e}}-\pi^{3}\right)\left(\pi_{\mathrm{t}+1}^{\mathrm{e}}-\pi^{4}\right)\right\}\right]^{-1}$ based on the non-linear IV estimates reported in Table 1a

Figure 1b) Estimates of $\theta$

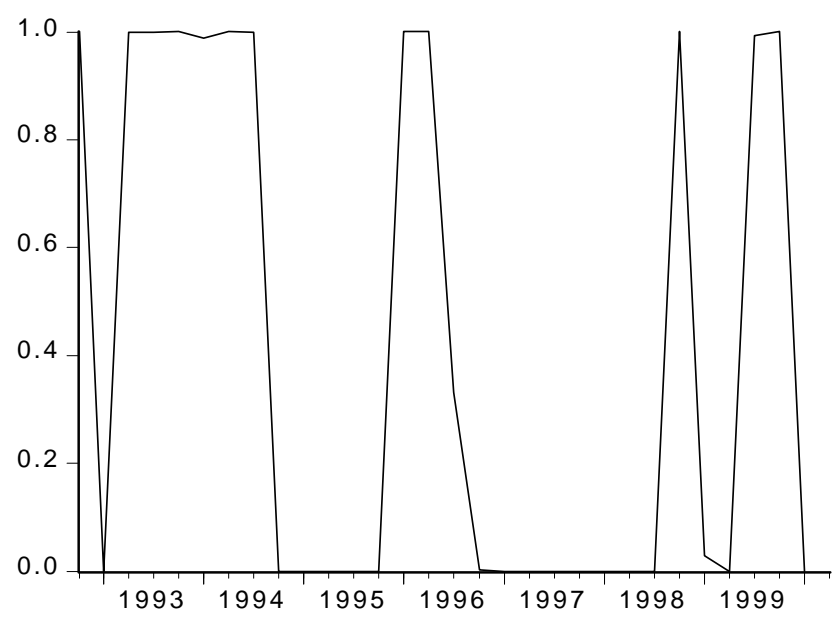

Note: $\theta_{\mathrm{t}}=1-\left[1+\exp \left\{-\sigma\left(\pi_{\mathrm{t}+1}^{\mathrm{e}}-\pi^{\mathrm{T}}-\pi^{1}\right)\left(\pi_{\mathrm{t}+1}^{\mathrm{e}}-\pi^{\mathrm{T}}-\pi^{2}\right)\right\}\right]^{-1}$ based on the non-linear IV estimates reported in Table $1 \mathrm{~b}$ 
Figure 2a) Expected inflation and bounds, 1992Q4-2000Q1

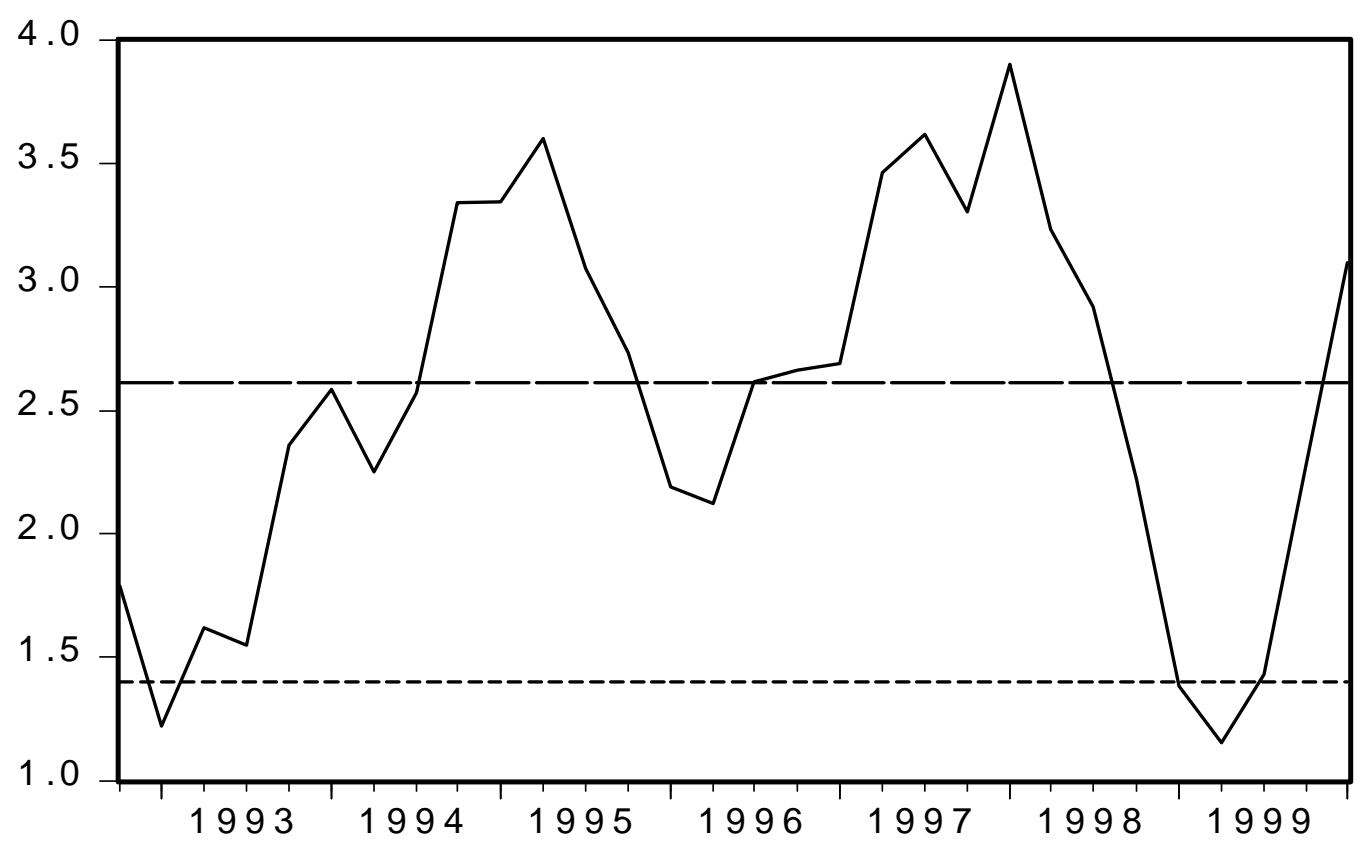

Notes:

—: expected inflation $\pi_{\mathrm{t}+1}^{\mathrm{e}}$

----: lower bound $\pi^{\mathrm{T}}-\pi_{1}=1.4 \%$

- — - : upper bound $\pi^{\mathrm{T}}+\pi_{2}=2.6 \%$

Figure 2b) The impact of expected inflation on the interest rate, 1992Q4-2000Q1

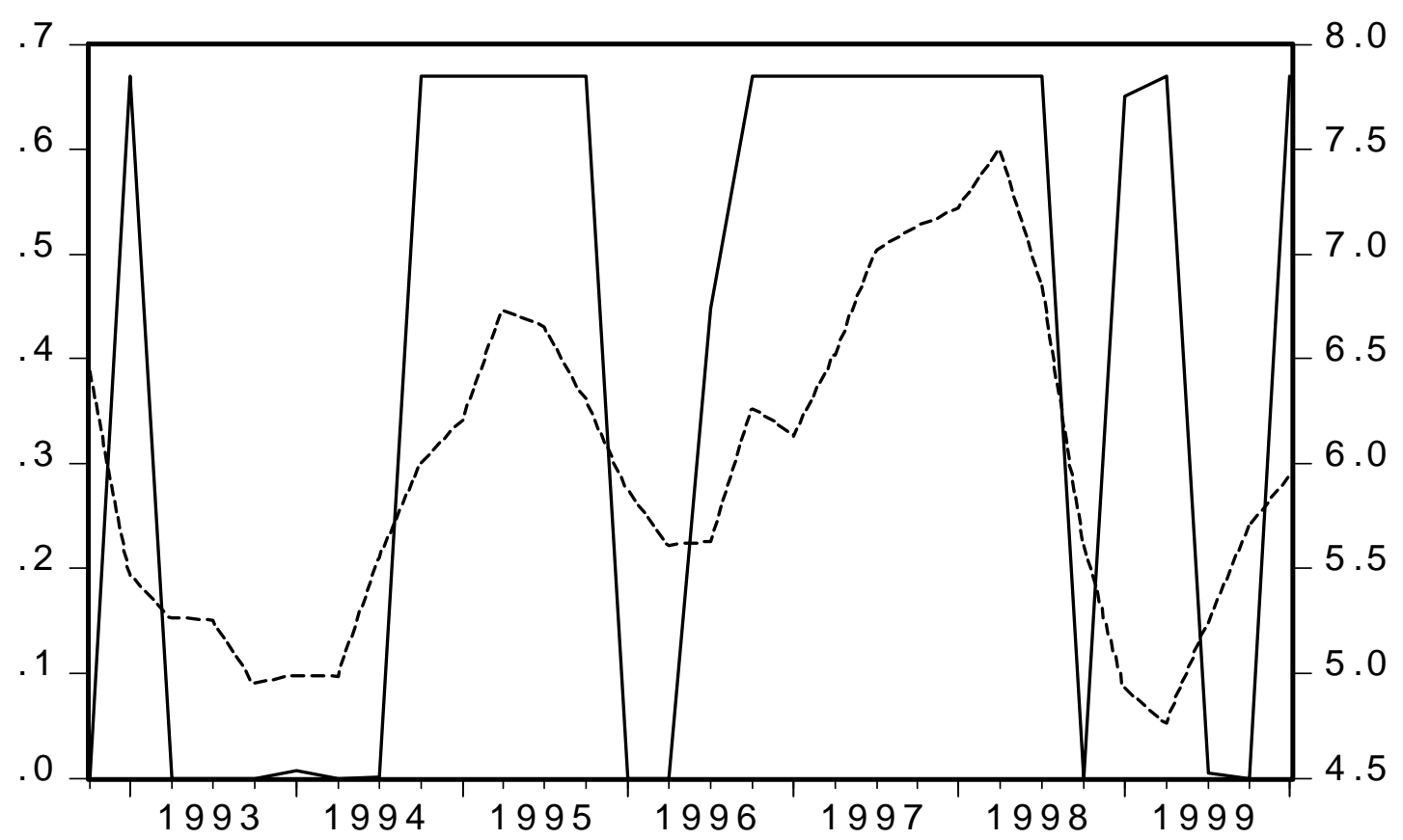

Notes:

- $\rho_{\mathrm{t}}=\theta_{\mathrm{t}} \alpha_{2}+\left(1-\theta_{\mathrm{t}}\right) \beta_{2}$ using the non-linear IV estimates reported in Table $1 \mathrm{~b}$.

----: interest rate $i_{\mathrm{t}}$. LHS axis: measurement units of $\rho_{\mathrm{t}}$. RHS axis: measurement units in $\%$. 


\section{References}

Batini, N. and A. Haldane, 1999, "Forward-looking rules for monetary policy", in J. Taylor (ed.), Monetary policy rules, National Bureau of Economic Research

Bec, F., Salem, M.B. and Collard, F. (2000). "Nonlinear economic policies: Pitfalls in the Lucas critique empirical counterpart", working paper, Universitie de Cergy-Poontoise

Bernanke, B., T. Laubach, F. Mishkin and A. Posen, 1999, Inflation targeting: lessons from the International Experience, Princeton University Press

Clarida, R., J. Gasli and M. Gertler, 1998,"Monetary policy rules in practice", European Econokmic Review, 42:6, pp 1033-67

Corbo, V., O. Landerretche Moreno, and K. Schmidt-Hebbel, "Assessing inflation targeting after a decade of world experience", paper presented at Bank of Chile conference on inflation targeting

Driver, R.L., Greenslade, J. and Pierse, R. (2000), "Goldilocks and new paradigm economics: the role of expectations in fairytales", mimeo, Bank of England

Fuhrer, J.C. (1997). "The (un)importance of forward-looking behavior in price specifications", Journal of Money, Credit, and Banking, vol. 29, pp. 338-350.

Fuhrer, J.C. and Moore, G.R. (1995). 'Inflation persistence'. Quarterly Journal of Economics, vol. 110, pp. 127-159.

Granger, C.W.J. and Teräsvirta, T. (1993). Modelling Nonlinear Economic Relationships. Oxford University Press, Oxford.

Hendry, D.F. (2001). 'Modelling UK Inflation, 1875-1991'. Journal of Applied Econometrics, vol. 16 , pp. $255-275$.

Hendry, D.F. and Doornik, J.A. (1997). Modelling Dynamic Systems Using PcFiml 9.0 for Windows. London: International Thomson Business Press.

Jansen, E.S. and Teräsvirta, T. (1996). 'Testing parameter constancy and super exogeneity in econometric equations' Oxford Bulletin of Economics and Statistics, vol. 58, pp. 735-768.

King, M., 1997, "The inflation target five years on", Bank of England Quarterly Bulletin, 37: pp 434-42

Mishkin, F. and A. Posen, (1997), "Inflation targeting: lessons from four countries", Federal Reserve Bank of New York Review, pp 9-110

Mishkin, F. and K. Schmidt-Hebbel, 2001, "One decade of inflation targeting in the world: what do we know and what do we need to know?", paper presented at Bank of Chile conference on inflation targeting

Nelson, E. (2000). 'UK monetary policy 1972-1997: a guide using Taylor rules'. Bank of England Working Paper No. 120. 
Rudebusch, G. and L. Svensson, 1999, "Policy rules for inflation targeting", in J. Taylor (ed.), Monetary policy rules, National Bureau of Economic Research

Svensson, L., 1997, "Inflation forecast targeting: implementing and monitoring inflation targets", European Economic Review, 41 (6): pp 1111-46

Svensson, L.,1997a, "Optimal inflation targets, conservative Central Banks and linear inflation contracts", American Economic Review

Taylor, J, 1993, "Discretion versus policy rules in practice", Carnegie-Rochester Conference Series on Public Policy, 39, pp 195-214

Teräsvirta, T. (1994). 'Specification, estimation, and evaluation of smooth transition autoregressive models'. Journal of the American Statistical Association, vol. 89, pp. 208-218.

Teräsvirta, T. (1998). Comment on 'The demand for broad money in the United Kingdom, 18781993 ' by Ericsson, N.R., Hendry, D.F. and Prestwich, K.M, Scandinavian Journal of Economics, vol. 100, pp. 325-328.

van Dijk, D., Teräsvirta, T. and Franses, P.H. (2001). 'Smooth transition autoregressive models - a survey of recent developments'. Econometric Reviews (forthcoming). 